\title{
A Sociological Study On Impact Of TB Among Women Patient In Karachi
}

\author{
Sakina Riaz \\ Department of Social Work \\ University of Karachi
}

\begin{abstract}
This study explores the phenomenon of the impact of TB among women Tuberculosis patients in Karachi.The objective of the study is to describe the socio-economic consequences of tuberculosis (TB) with special reference to gender differentials concerning social stigma among women TB patients, in Karachi. A descriptive study was conducted from Ojha Institute of Chest Diseases, Karachi. Both quantitative and qualitative methods for data collection were utilized. All the patients were interviewed according to a pre-designed \& pre-tested questionnaire and after taking informed consent of the patients. The sampling was done by Purposive Sampling Method. Inclusion criteria were patients above 18 years, with hospital diagnosed active pulmonary tuberculosis. Twenty - Eight patients were selected as sample for this study. The data was collected and analyzed after processing into MS excel sheets for statistical analysis.

The study has demonstrated that the stigma in tuberculosis still remains a problem and strong efforts are required in advocacy, communication and social mobilization for reducing the stigma problem among TB patients in effective control of tuberculosis.
\end{abstract}

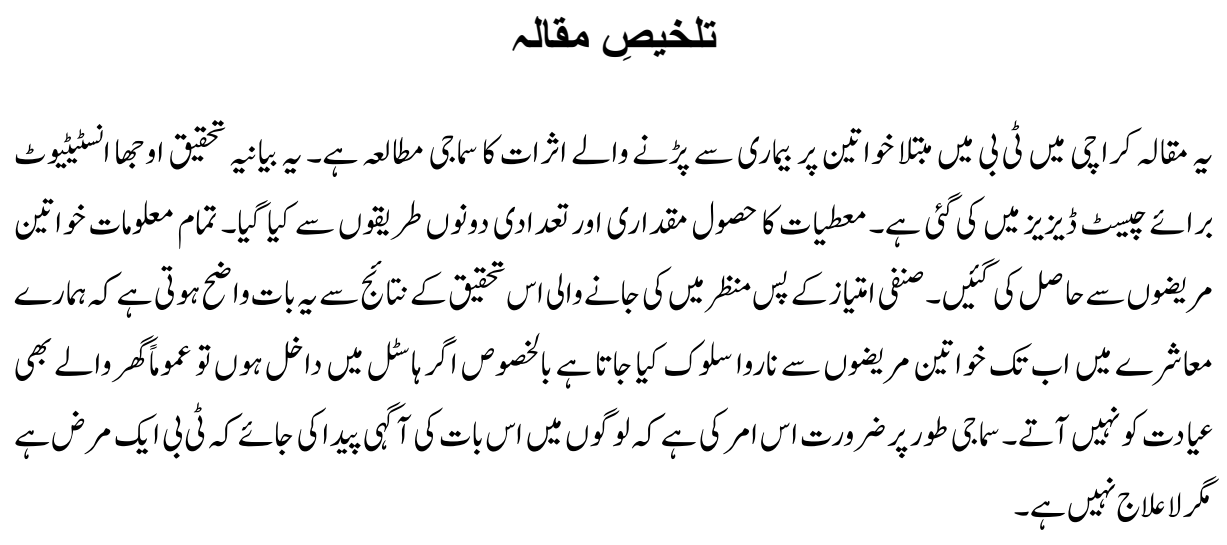

\section{Introduction}

Tuberculosis (TB), an airborne infectious disease, is the third leading cause of death for women worldwide. In some parts of the world TB has been eradicated, but low detection rates and poor treatment rates are still an issue in developing countries. Early detection and effective cure protocol are important determinants of disease control. 
Tuberculosis (TB) kills about one million women per year and it is estimated that almost one billion women and girls are infected with TB. Gender aspects of tuberculosis have been neglected in research area, and little attention has been given to these aspects of tuberculosis control. Women experience different risk factors, social and economic consequences, and barriers to treatment than men. Yet little has been done to address the biological differences and gender disparities and difference in social status as described by the society at any given set - up, this present a unique challenge to the diagnosis and treatment of TB in women.

As tuberculosis affects women mainly in their economically and reproductively active years age (15-44), the impact of the disease is also strongly felt by their children and families. Poverty and lack of information are the major factors for developing active TB disease. Because women account for 70 percent of the world's poor, women in developing countries are disproportionately affected by the disease.(World Health Organization, 2011)

In 2008, 3.6 million women developed $\mathrm{TB}^{\mathrm{i}}$ and approximately another 500,000 died as a result. (World Health Organization, 2009b)

TB is a classical example of a disease with both medical and social dimensions, characterized by its close relation to poor socio-economic conditions. (WHO, 2009b)

Patients living with tuberculosis (TB) experience significant psychological, economical, cultural and social sufferings .Amongst problems met by TB patients, social stigma and discrimination has been increasingly recognized. This situation impacts on treatment adherence by individual patients and on disease control especially in developing nations. Goffman E (1963), stated that social stigma is "an undesirable or discrediting attribute that an individual possesses, thus reducing that individual's status in the eyes of society". Link B, Phelan J, (2001) describes stigma as a process that begins when a particular trait or characteristic of an individual or group is identified as being undesirable or disvalued. The situation is become more, sensitive or critical in the case of a particular disease. According to Grange, J. Story A and Zumla A.(2001), "The stigma associated with the disease often leads to seeking delayed treatment and poor adherence to Therapy".

The social determinants of health refer to the institutional, community, and interpersonal factors that affect health outside of the ease with which an individual can access medical services. (WHO, 2008)

Stigma, which is shaped and promulgated by institutional and community norms and interpersonal attitudes, is a social determinant of health. (Heijnders M, Van Der Meij S, 2006) 
The social impact of TB on women is quite serious because they are at the bottom of everything whether it comes to health services or economic empowerment and whether it is access to food and nutrition. Although, women has been a topic of discussion and neglected since long, although she plays a vital role in the house, caring for the family and outside as well as still she is considered less capable. It is observed that in our society, most of the time women have been the victim of exploitation and discrimination and is being treated as an inferior gender.

With regard to gender discrimination in health care, Women are really in the bottom strata of the society, and, coupled with that is the effect of gender discrimination against women. There is no equal opportunity, so it affects a lot of women. Access to health is a big problem for women. In Pakistan traditionally there is a practice that women always receive less food than men within the family. Whereas biologically, women often have greater nutritional needs than men because of long hours of working in house, pregnancy and lactation.

It is true that tuberculosis is affecting everyone in the society, but women tend to suffer a lot more just because their access to healthcare is so low. In fact, the health-seeking behavior of women is very poor in the communities in Pakistan, This issue seldom discussed and it is the fact that women are likely to wait longer than men before they seek medical attention because of the social stigma attached to TB. There is a dire need to involve women in empowerment process and to help them to understand that their own health is important. They must begin to put their own health first rather then putting their family first and neglecting their own health as they are facing a severe burden.

\section{Social and Economic Consequences of TB in Women}

- Socially, the stigma of having TB falls more heavily on women than men. It causes substantial burden on women and their families. Women suffering from TB are often unable to care for their children and have trouble performing household chores. Children are often forced to leave school to care for ailing parents and relatives.

- Women with TB are often too ill to engage in work outside the home, leading to a loss of wages due to this disease.

- Poverty is a major factor for developing active TB disease. Of the 22 countries that are home to 80 percent of the world's people with active TB, while 17 have an annual Gross Domestic Product (GDP) of less than US \$760.8 Because women account for 70 percent of the worlds poor, women in developing countries are disproportionately affected by the disease.(United Nations Development Fund for Women ,2010) 
- Delayed TB diagnosis in pregnant women enhances the chance of death during childbirth and causes danger to the child.

- $\quad$ Studies from Mexico and India indicate that TB positive women are twice as likely to give birth to a premature or low-birth-weight baby and four times more likely to die during childbirth. The risk of infant death also greatly increases (Lin, H.C. and Chen, S.F. ,2010).

- $\quad$ Some women stop taking their medication because they fear it will affect their breast milk and/or unborn baby.( Hudelson, P. ,1996)

- Discontinuing TB medication prematurely is a serious hazardous to pregnant women and their babies also and can lead to the development of drug resistant TB. If left untreated, women may transmit TB to their infant or other children and family members.

- In low income countries women tend to self medicate or seek out traditional healers instead of accessing public TB clinics because they are afraid of being recognized as a TB patient by members of the community. (Thorson, A., Hoa, N.P. Long NH., 2000).

- In some cases women neglected their illness until they became too sick to lead normal lives and, in some case, too sick to seek medical attention. (Atre S.R., Kudale A.M. et al., 2004).

- Social factors also contribute to the disparity in case detection between men and women. A study in Pakistan reported that women felt uncomfortable producing the mucus needed for sputum-smear microscopy, the standard diagnostic test for TB in resource-limited settings (Khan, M. et al. 2007).

\section{Important Factors of Stigma and Socio - Economic Impact of TB on Woman}

The Status of women often have a lower socio-economic status specially in low-income countries which leads to, reduced access to economic resources, and fewer educational opportunities as compared to men. As a result, many women are unable to locate and reach qualified health services (Long, NH et al., 2001). There is a fact that no society in the world treats men and women on equal basis (UNDP, 1997)

Positive TB diagnoses have damaging consequences for women. Socially, the stigma of having TB falls more heavily on women than men. In some communities, a positive TB diagnosis may force women into divorce or, if unmarried, create difficulty in finding a marriage partner (Waisbord, 2005).

In addition to stigma, TB has a profound affect on women and their families. Because TB mostly affects women in their economically and reproductively active years, the impact of the disease is strongly felt at home where her personal and social life is disturbed. In Pakistan, it is a practice that women often cook indoors in very confined spaces using 
biomass fuel such as wood or animal dung. Studies show that women who cook with these fuels are more likely to develop active TB. (Mishra, et al.1999). Evidence suggests these fuels can weaken women's respiratory systems and impair the immune system's ability to fight off bacteria.

Women who are infected with $\mathrm{TB}$ bacteria are more likely to develop infectious $\mathrm{TB}$ disease than men. Following are the important and contributing factors that lead to delays in TB treatment and have an impact on Women with special reference to Pakistani society:

1. Woman's ability to recognize symptoms of TB

2. Less Access a proper health care facility

3. Fear of stigma and Isolation.

4. Cost of Treatment or non -affordability for Treatment expenses.

5. Lack of education.

6. Women Position in Family.

7. Over crowding

8. Poor Nutritional Status

9. Lack of education,

10. A weaker socio-economic status.

11. Unemployment / Jobless or Limited financial resources

12. Large Family Size and poverty.

Women suffering from TB are often unable to take proper care for their children and have many troubles in performing household chores. Research suggests children are more likely to become infected with TB if their mother has TB than if their father has the disease. In some fatal TB cases women leave behind orphaned children. The social and economic consequences of TB often overlap. In addition to household chores and caring for children, many women engage in work outside the home. Many women work in the agricultural or domestic sector, providing necessary additional household income. As a result, TB disease leads to a loss of work and loss of wages.

\section{Review of Related Literature}

The role of human behavior in health and illness has been increasingly recognized. Health is no longer considered simply as a biomedical problem; rather, it is influenced by social, cultural, physiological, economic and political factors that determine the behavior of the people concerned. Hence, the interaction of the health behavior of the people with the behavior of the health worker - in addition to more conventional medical factors - all work to determine the progress of disease and its ultimate solution.( WHO. April 1986.) 
Several models have been proposed to account for health behaviors and sustained behavioral changes. Although they may differ in content and perspective, models for behavior change stress the importance of evaluating the stigma associated with the disease. A proper assessment and understanding of impact factors in women patients is particularly helpful in the area of chronic and highly communicable disease such as Tuberculosis.

It is a fact that TB is the biggest infectious disease killer of women of child-bearing age. Studies conducted on the socio-economic impact of TB have projected that over three hundred thousand children are orphaned by the disease every year, while over a one hundred women are rejected by their families, they have a pressure and for fear of social isolation, harassment and divorce , once they contract this disease.

In a study from Vietnam (Johansson, 2000) indicated that despite suffering from TB disease, men were supported and treated with respect by other family members, while women were sometimes threatened, humiliated and subjected to divorce. This has also been described by Liefooghe et al. (1995) from his research that when women were subjected to divorce because of TB disease.

Also Nair et al. (1997) has reported from India how women were concerned about rejection by husbands, harassment by in-laws and reduced chances of marriage, if single.

The power sphere of women is restricted to household chores, child rearing and expenses for daily meals. The household income and large expenditures are often controlled by husbands (Anh, 1991). The husband is seen as the head of the family. Female subordination in the family is closely linked to their subordinate economic roles (Liljestrom, 1991).

In short, in our society women do not identify their needs or find it difficult to defeat social and cultural barriers in relation to finding health services. Delay in accessing health services for women is attributed to the subordination of women in the family economic strategies.

\section{Methodology}

This study was hospital based study. Purposive sampling technique was used in this study as the researcher was interested only in those female patients who had a problem of TB and have hospitalized at Ojha Institute of Chest Disease from $15^{\text {th }}$ November 2012 to $15^{\text {th }}$ December 2012. Twenty eight respondents were interviewed; sing self-administered questionnaires to collect each respondent's data. Results of the study were as follow: 
Table -01

Frequency and percentage Distribution of Respondents According to their affect in Relationships with others

\begin{tabular}{|l|c|c|}
\hline & Frequency & Percentage \\
\hline Yes & 24 & 85.7 \\
\hline No & 1 & 3.6 \\
\hline Don't Know & 3 & 10.7 \\
\hline Total & $\mathbf{2 8}$ & $\mathbf{1 0 0}$ \\
\hline
\end{tabular}

Table -02

Frequency and percentage Distribution of Respondents According to their Lifestyle Being a TB patient, would you prefer to live isolated?

\begin{tabular}{|l|c|c|}
\hline & Frequency & Percentage \\
\hline Yes & 6 & 21.4 \\
\hline No & 14 & 50.0 \\
\hline Don't Know & 8 & 28.6 \\
\hline Total & $\mathbf{2 8}$ & $\mathbf{1 0 0}$ \\
\hline
\end{tabular}

Table -03

Frequency and percentage Distribution of Respondents According to affects of TB on marital relationship

\begin{tabular}{|l|c|c|}
\hline & Frequency & Percentage \\
\hline Yes & 18 & 64.3 \\
\hline No & 1 & 3.6 \\
\hline Don't Know & 9 & 32.1 \\
\hline Total & $\mathbf{2 8}$ & $\mathbf{1 0 0}$ \\
\hline
\end{tabular}

Table -04

Frequency and percentage Distribution of Respondents According to the affect of TB in performing family responsibilities

\begin{tabular}{|l|c|c|}
\hline & Frequency & Percentage \\
\hline Yes & 28 & 100.0 \\
\hline
\end{tabular}

Table -05

Frequency and percentage Distribution of Respondents According to their Perception regarding Chance of Marriage

\begin{tabular}{|l|c|c|}
\hline & Frequency & Percentage \\
\hline Yes & 16 & 57.1 \\
\hline Don't Know & 12 & 42.9 \\
\hline Total & $\mathbf{2 8}$ & $\mathbf{1 0 0}$ \\
\hline
\end{tabular}


Table -06

Frequency and percentage Distribution of Respondents According to their Knowledge about Female infertility

\begin{tabular}{|l|c|c|}
\hline & Frequency & Percentage \\
\hline Yes & 10 & 35.7 \\
\hline No & 1 & 3.6 \\
\hline Don't Know & 17 & 60.7 \\
\hline Total & $\mathbf{2 8}$ & $\mathbf{1 0 0}$ \\
\hline
\end{tabular}

Table -07

Frequency and percentage Distribution of Respondents According to their Feelings about TB

\begin{tabular}{|l|c|c|}
\hline & Frequency & Percentage \\
\hline Felt Sorry & 5 & 17.9 \\
\hline Scared & 10 & 35.7 \\
\hline Worried about work & 5 & 17.9 \\
\hline Worried about children & 2 & 7.1 \\
\hline Uneasiness & 1 & 3.6 \\
\hline Did not feel anything & 5 & 17.9 \\
\hline Total & $\mathbf{2 8}$ & $\mathbf{1 0 0}$ \\
\hline
\end{tabular}

Table -08

Frequency and percentage Distribution of Respondents According to their Knowledge about affect of TB during Pregnancy

\begin{tabular}{|l|c|c|}
\hline & Frequency & Percentage \\
\hline Yes & 9 & 33.3 \\
\hline Don't Know & 18 & 66.7 \\
\hline Total & $\mathbf{2 7}$ & $\mathbf{1 0 0}$ \\
\hline
\end{tabular}

Table -09

Frequency and percentage Distribution of Respondents According to their relatives/ friends' visit to hospital

\begin{tabular}{|l|c|c|}
\hline & Frequency & Percentage \\
\hline Yes & 9 & 32.1 \\
\hline No & 17 & 60.7 \\
\hline Don't Know & 2 & 7.1 \\
\hline Total & $\mathbf{2 8}$ & $\mathbf{1 0 0}$ \\
\hline
\end{tabular}


Table -10

Frequency and percentage Distribution of Respondents According to their stigma and discrimination

\begin{tabular}{|l|c|c|}
\hline & Frequency & Percentage \\
\hline Yes & 24 & 85.7 \\
\hline No & 1 & 3.6 \\
\hline Don't Know & 3 & 10.7 \\
\hline Total & $\mathbf{2 8}$ & $\mathbf{1 0 0}$ \\
\hline
\end{tabular}

\section{Findings \& Discussion}

This study was conducted among Women TB patients who were admitted to Ojha Institute of Chest Disease, Karachi. A total of 28 female patients were included in this study. Most of the patients were from lower or middle class / income group. They were either jobless at the time of their hospitalization/ treatment of TB, or had very little income and could not able to meet their financial expenses.

Majority of the respondents were illiterate (32.1\%), married (67.8\%), and aged 18-28 years old (39. 2\%). 35.6\% of the respondents were housewives while $(21.4 \%)$ have been engage in financial responsibilities as Daily wage earner. Almost all the respondents are aware of the usual signs and symptoms of TB, like cough, chest and back pains, on and off fever.

Attitudes and Practices toward TB Patients, Diagnostic, Treatment (74.1\%) Seventy Four point one percent of the respondents (20) don't think that TB should be feared or be ashamed of. Almost everyone (86.4\%) believe that anybody can get infected, but also that he can recover as long as medicines are taken according to prescribed dosage and duration. $100 \%$ respondents believed that $\mathrm{TB}$ affects on their family responsibilities. $(57.1 \%)$ of the study respondents viewed that there are less chances of getting married due to TB .

The matter pertaining to the patients' awareness regarding Breast feeding, Lack of awareness regarding breast feeding among women was observed. Sixteen respondent of the study $(59.3 \%)$ were no knowledge, where as $(40.7 \%)$ have a clear understanding regarding the matter. Lack of awareness regarding breast feeding among mother / women was observed.

It was expressed with great concerned by 17 respondent ( $60.7 \%)$ that their relatives and friends do not pay visit to the TB patients during their hospital stay for treatment.(hospitalization).they further disclosed that after their diagnoses become 
known in family and friend, they are avoiding them. Patient's respondent to these attitudes by isolating themselves and becoming more sensitive and aggressive.

A large number of respondents $(85.7 \%)$ were highlighted that females get difficulty to be treated for TB in our society. Twenty five respondents $(89.3 \%)$ were viewed that TB affects relationship with friends and other community members. While asking about TB disclosure among relatives and friends, 76.4\% respondent. Nearly all (96.4\%) perceived that Tuberculosis affects their capacity for work performance, and Eighteen respondents (64.3\%) mentioned that its do affect their marital life as well. Refer to the question related to the treatment cost $(82.1 \%)$ pointed out that the treatment is very costly and long duration of disease.

\section{Recommendations}

The study made several recommendations including there is a felt need to appropriate change in the way of living and behavior of society as whole. It is highlighted through this study that social factors play an important role in the care and management of TB patients. The stigma associated whit is disease often leads to seeking delayed treatment especially in women.

Misconceptions with TB and the cultural barriers are the main causes of undesirable behavior towards TB patients, which leads to the frustration in patients. It is also a main reason for stopping patients from attending social functions and segregated them from the family and social gatherings.

TB affects women mainly during their economically and reproductively active years, causing a substantial burden on children and families. Immediate action is needed to address the suffering TB causes and elimination of the disease.

All pregnant women should be screened for TB and provided appropriate treatment and care, if required. Routine TB screening should be incorporated into maternal and child health programs.

There is an urgent need to start a gender based approach for tuberculosis control programmes as it will help to understand the disease itself and in its eradication.

It is also suggested that educational $\backslash$ counseling program should be designed for TB patients' family members and efforts should be made for actively involvement in cure and rehabilitation of Patients, without family support we can not defeat TB from Pakistan. 


\section{Conclusions}

The findings of the study are based on the knowledge levels of socio-economic consequences and stigma among women TB Patients in Karachi, similar studies are needed to be conducted in other hospital wettings as well as from different community at the national level and International level for recommending appropriate changes in Public behavior towards female TB patients.

There is an need to strengthen the National Tuberculosis Progarmme, particularly its health education component. The present study is conclude that the long course of TB treatment is a complex, dynamic phenomenon with a wide range of social, psychological, economical factors impacting on treatment-taking behaviour. This situation is become more serious when the patient is admitted in hospital. Female TB Patients' hospitalization was influenced by the interaction of a number of these factors. The findings of the present study highlight the need to further increase the knowledge levels of TB patient, particularly in women.

\section{References}

Anh DN. (1991). The position of women in two rural communes. In: Liljestrom R, Lai T,editors. Sociological studies on the Vietnamese family. Hanoi: Social Sciences Publishing House, 165-74.

Atre S, Kudale A, Morankar S, Gosoniu D, Weiss MG (2011) Gender and community views of stigma and tuberculosis in rural Maharashtra, India. Glob Public Health 6: $56-71$.

Goffman E. (1963) Stigma: notes on the management of spoiled identity. New York Simon \& Shuster.

Grange, J. Story A and Zumla A. (2001) Tuberculosis in disadvantaged groups. Curr Opin Pulm Med, 7:160.

Heijnders M, Van Der Meij S. (2006) The fight against stigma: an overview of stigmareduction strategies and interventions. Psychol Health Med; 11:353-63.

Hudelson, P. (1996). "Gender Differentials in Tuberculosis: The Role of Socio-economic and Cultural Factors." Tubercle and Lung Disease 77(5): 391-400. Henceforth: Hudelson 1996. 
Jaggarrajamma K, Ramchandran R, Charles N,Chandrasekaran V, Muniuandi M and Ganapathy S. (2008) Psychosocial dysfunction: Perceived and enacted stigma among tuberculosis patients registered under RNTCP. Indian J Tuberc; 55: 17987.

Johansson E, Long NH, Diwan VK, Winkvist A. (2000) Gender and tuberculosis control: perspectives on health seeking behaviour among men and women in Vietnam. Health Policy May;52(1):33-51.

Khan MS, Dar O, Sismanidis C, Shah K, Godfrey-Faussett P. (2007) Improvement of tuberculosis case detection and reduction of discrepancies between men and women by simple sputum-submission instructions: a pragmatic randomized controlled trial. Lancet.; 369:1955-1960.

Liefooghe R, Michiels N, Habib S, Moran MB, de Muynck A. (1995) Perception and social consequences of tuberculosis: a focus group study of tuberculosis patients in Sialkot, Pakistan. Soc Sci Med 41(12):1685-1692.

Liljestrom R. (1991) Family, Gender and Kinship in Vietnam. In: Liljestrom R, Lai T, editors. Sociological studies on the Vietnamese family. Hanoi: Social Sciences Publishing House; p. 13-24.

Lin, H.C. and Chen, S.F. (2010) "Increased Risk of Low Birth weight and Small for Gestational Age Infants Among Women With Tuberculosis." BJOG: An International Journal of Obstetrics and Gynaecology 117(5): 585.

Link B, Phelan J. (2001) Conceptualizing stigma. Annu Rev Sociology 27:363-85.

Long NH, Johansson E, Diwan VK, Winkvist A. (2001) Fear and social isolation as consequences of tuberculosis in VietNam: a gender analysis. Health Policy.58:69-81.

Mishra, V.K., Retherford, RD. \& Smith, KR (1999). "Biomass Cooking Fuels and Prevalence of Tuberculosis in India." International Journal of Infectious Disease 3(3): 119-29.

Nair DM, George A, Chacko KT. (1997) Tuberculosis in Bombay: new insights from poor urban patients. Health Pol Plann 12(1):77-85. 
Thorson, A., Hoa, N.P. Long NH (2000). "Health Seeking Behaviour of Individuals With a Cough of More Than 3 Weeks." The Lancet 356(9244): 1823-24. 19 Long et al. 2001.

UNDP (1997) Human Development Report 1997, oxford and NewYork, Oxford University Press, p.7

United Nations Development Fund for Women (2010).Women, Poverty and Economics. Online, United Nations Development Fund for Women. http://www.unifem.org/gender_issues/women_poverty_economics>.

Waisbord, S. (2005). Behavioral Barriers in Tuberculosis Control: A Literature Review. Washington, D.C., The CHANGE Project / Academy for Educational Development. Accessed : <http://pdf.usaid.gov/pdf_docs/Pnadf406.pdf>.

WHO. (1986) Concept of Health Behavior Research - South East Asia Advisory Committee in Medical Research. WHO/ SEARO.

World Health Organization (2009b). 36 Million People With TB Cured. Online, World Health Organization. Accessed: ttp://www.who.int/mediacentre/news/releases/ 2009/tb_report_20091208/>.

World Health Organization (2009b). 36 Million People With TB Cured. Online, World Health Organization. <http://www.who.int/mediacentre/news/releases/2009/tb report_20091208/>.

World Health Organization, (2008) Commission on Social Determinants of Health. Closing the gap in a generation: health equity through action on the social determinants of health. Final report of the Commission on Social Determinants of Health. Geneva: WHO;2008.

World Health Organization. (2011). Global Tuberculosis Control Report 2011. Geneva: World Health organization.

Ms. Sakina Riaz is Assistant Professor in the Department of Social Work, University of Karachi. 